\title{
Featural-visual Indexicality and Sound-shape Congruency in a Phonologically Engineered Alphabet
}

\author{
Marcia S. Suzuki, M.A. ${ }^{1}$ \\ ${ }^{1}$ University of the Nations
}

August 24, 2021

\begin{abstract}
The term uniskript was coined to refer to a class of phonologically engineered alphabets that employ visual-featural indexicality combined with sound-shape congruency to represent speech. In this working paper, I introduce the uniskript methodology, an alphabet generator technique that uses indices instead of symbols to represent the flow of speech. I refer to the Peircean theory of signs to explain the crucial semiotic distinction between uniskript and the traditional alphabets: in uniskript, an icon resembling relevant articulatory features of a given phoneme is used to index sound to shape. I also indicate how the findings in sound-symbolism were incorporated into the indices to facilitate cross-modal correspondences. I propose that uniskript indexical nature and sensorial mappings can explain why it is so much easier to learn than symbolic and sensory incongruent alphabets. I then briefly discuss how the study of uniskript alphabets can shed some light on the role of cross-modal correspondences in learning. It can also bring a deeper understanding of the role of phonology in sound symbolism. Finally, I refer to some applications of uniskript in the teaching of literacy and in remediating reading issues and illustrate the entire concept by introducing a uniskript alphabet developed as a tool to teach pronunciation in an ESL program.
\end{abstract}

keywords: uniskript, alphabets, sound symbolism, sound-shape iconicity, cross-modal congruency, phonology, second language learning, pronunciation in L2

(C) 2018 Marcia S. Suzuki - Uniskript Alphabets www.uniskriptalphabets.com

This paper is protected under a Creative Commons Attribution-NonComercial-ShareAlike 4.0

International License

\section{Introduction}

Back in the Mid Bronze Age, an unexpected aha moment prompted Cananite turquoise miners to use Egyptian hieroglyphs to write the words of their own language (Rico, 2015). Their "experiment" gave origin to Proto-Phoenician, the first alphabet, which evolved into many modern alphabets, including the Roman letters used to write the present working paper. The newly acquired possibility of representing the somewhat abstract but numerically limited sounds of a language, instead of an infinite number of concepts or words, was a game changer in the history of writing. However, as the systems morphed from icons into symbols, they lost their mnemonic strength.

Language representation is not an easy endeavor. The flow of speech is perceived acoustically and constitutes a multitude of distinct audible vibration waves that propagate in the air. Different civilizations have devised 
distinct systems to represent language by means of visual signs. In order to address the semiotic nature of those systems, we need to shortly refer to the Peircean Semiotics and its three types of signs: symbols, icons, and indices. (Plowright, 2015)

Symbols are signs that are culturally constructed, need to be agreed upon, and then memorized by its users. The Roman letter $\mathbf{f}$ is a symbol; its relation to the sound it represents is arbitrary. Icons, conversely, are signs that resemble the object they represent. The ancient Chinese character for rain was iconic, easy to learn because it looked like rain. Its logic was not based on representing the flow of speech per se, but the concepts referred to by it.

Indices, or indexes, however, follow a different logic. They are not arbitrary but do not resemble the referent either. They are signified by posing a direct link between them and the object they represent. Uniskript signs are indexical because they refer to speech sounds, which are physical waves, by pointing to the articulatory features that produce them.

The three different types of signs are illustrated in Figure 1, with an arrow indicating a continuum of abstraction from left to right.

\begin{tabular}{|ccc|}
\hline & TYPES OF SIGNS & \\
\hline SYMBOL & INDEX & ICON \\
\hline $\begin{array}{c}\text { Roman } \\
\text { Letter } e m \text { in the } \\
\text { English alphabet }\end{array}$ & $\begin{array}{c}\text { Uniskript glyph for a } \\
\text { bilabial nasal } \\
\text { phoneme }\end{array}$ & $\begin{array}{c}\text { Ancient Chinese } \\
\text { pictograph for rain }\end{array}$ \\
\cline { 2 - 3 } & LEARNABILITY \\
\hline
\end{tabular}

Figure 1: The uniskript index for a bilabial bilabial nasal phoneme resembles the closed lips and the nostrils.

In terms of learnability, symbols are more difficult to learn because they are arbitrary - they have to be rote memorized. Icons, on the other end of the continuum, are more intuitive because they visually resemble the referent. The problem in using icons to represent language is that thousands of icons are necessary to cover all possible words in a given language. Besides that, abstract concepts and grammar are not always easy to represent iconically. An indexical system, however, like uniskript, combines the easiness of a pictorial system with the economy of an alphabetic system. This versatility explains why people learn uniskript so much faster than Roman letters, on one end, or Chinese characters, on the other.

In the next sections, I will shortly describe how uniskript alphabets are generated and discuss their applica- 
tions in the area of education, literacy, phonics and second language learning.

\section{Featural-visual Indexicality}

Contrary to the spontaneous evolvement of most traditional alphabets, uniskript alphabets are generated through the meticulous work of a trained developer using a phonological matrix called 4-Questions Technique.(Suzuki)link Even though the principles are universal, uniskript alphabets are language specific. Each relevant phonological feature/gesture, of any given phoneme in the language, receives a bidimensional shape. Figures 2 and 3 illustrate the shapes suggested in the technique. The matrix prompts the developer with a set of questions and a number of alternative answers for each one of the features.

\begin{tabular}{|c|c|c|c|c|c|c|c|}
\hline \multicolumn{2}{|c|}{$\begin{array}{l}\text { What is the } \\
\text { constriction organ } \\
\text { (CO)? }\end{array}$} & \multicolumn{2}{|c|}{$\begin{array}{l}\text { Does the } \mathrm{CO} \text { undergo } \\
\text { any displacement of } \\
\text { articulation (DA)? }\end{array}$} & \multicolumn{2}{|c|}{$\begin{array}{c}\text { Is there any } \\
\text { simultaneous extra- } \\
\text { oral constriction (EOC)? }\end{array}$} & \multicolumn{2}{|c|}{$\begin{array}{l}\text { What is the } \\
\text { constriction degree } \\
\text { (CD)? }\end{array}$} \\
\hline Lips & $\ominus$ & dental & u & nasal & $\cdot$. & critical & $\approx$ \\
\hline tongue tip & $\Delta$ & $\begin{array}{l}\text { post- } \\
\text { alveolar }\end{array}$ & $>$ & voice & . & narrow & $\sim$ \\
\hline $\begin{array}{l}\text { tongue } \\
\text { body }\end{array}$ & 0 & lateral & $\curlywedge$ & rounded lips & $\circ$ & wide & - \\
\hline $\begin{array}{l}\text { tongue } \\
\text { dorsum }\end{array}$ & ר & retroflex & c & pharyngealization & " & & \\
\hline \multirow[t]{3}{*}{ larynx } & O & uvular & u & distended glottis & ๑ & & \\
\hline & & click & $*$ & $\begin{array}{l}\text { constricted } \\
\text { glottis }\end{array}$ & m & & \\
\hline & & $\begin{array}{l}\text { double- } \\
\text { articulation }\end{array}$ & 7 & glottalization & $\oplus$ & & \\
\hline
\end{tabular}

Figure 2: The 4-Questions Technique matrix for consonants

After answering each one of these four questions, the analyst will have arrived at what we call the protouniskript alphabet and will undergo a process of elimination of redundancy. Only the contrastive features required for distinguishing a phoneme from all other phonemes in the language will be kept in the final product. 


\begin{tabular}{|c|c|c|c|c|c|c|c|}
\hline \multicolumn{2}{|c|}{$\begin{array}{l}\text { What is the } \\
\text { Degree of Aperture } \\
\text { (DAp)? }\end{array}$} & \multicolumn{2}{|c|}{$\begin{array}{l}\text { Is there any } \\
\text { displacement of } \\
\text { articulation (DA)? }\end{array}$} & \multicolumn{2}{|c|}{$\begin{array}{l}\text { Is there any extra-oral } \\
\text { constriction (EOC)? }\end{array}$} & \multicolumn{2}{|c|}{$\begin{array}{l}\text { Is there any } \\
\text { Weight Device } \\
\text { (WD)? }\end{array}$} \\
\hline close & - & frontward & ᄂ & rounded lips & 。 & length & -- \\
\hline close-mid & $\equiv$ & backward & $\neg$ & nasal & .. & lenis & - \\
\hline mid & $\equiv$ & retroflex & s & pharyngealization & $\|$ & tone & $\backslash$ \\
\hline open-mid & $\equiv$ & & & distended glottis & 6 & gliding & $>$ \\
\hline open & 豆 & & & $\begin{array}{l}\text { constricted } \\
\text { glottis }\end{array}$ & $m$ & & \\
\hline
\end{tabular}

Figure 3: The 4-Questions Technique Matrix for Vowels

\title{
Sound-shape Congruency
}

Additionally, to the above referred indexical nature, uniskript signs are also sensory congruent. Each shape incorporates some of the cross-modal correspondences previously established in the literature of sound symbolism. Saussure's claims that there is no link between a thing and its name constitute the basis for one of the most fundamental assumptions of the modern linguistics: the arbitrariness of the linguistic sign (Lepschy, 1985).

Nevertheless, the debate about sound-shape-meaning symbolism is at least as old as Plato's 400 BC work called Cratylus (Baxter) . In this famous dialogue with Hermogenes, Cratylus hypothesizes that the movements of the mouth and tongue during the production of a sound somehow resemble some correlate semantic concepts. According to him, $[\mathrm{r}]$ would be naturally related to 'motion, rapidity' while [o] would naturally point to 'roundness'. Later, Sapir's research (Sapir, 1929) demonstrated that English speakers systematically associate the back vowel /a/ with 'largeness', but the front vowel /i/ with smallness. According to Monaghan et. al:

\begin{abstract}
"It is a long established convention that the relationship between sounds and meanings of words is essentially arbitrary - typically the sound of a word gives no hint of its meaning. However, there are numerous reported instances of systematic sound-meaning mappings in language, and this systematicity has been claimed to be important for early language development." (Monaghan et al., 2014)
\end{abstract}

The phenomenon of sound-shape symbolism was explored also by Köger (Fontana, 2013). His seminal experiment (1929) showed that most Spanish native speakers matched the nonword maluma with rounded shapes, and takete with angular shapes. The experiment, later called "kiki-bouba effect", as in Figure 4, was replicated across a wide range of unrelated languages and showed that people tend to match words and such figures far more often than chance would predict. 
Figure 4: Abundant research evidence demonstrates that the mapping between speech sounds and the visual shape of objects may not be arbitrary. Most people than what could be explained by chance, regardless of language, age, and location, would naturally call the shape on the left 'bouba' and the shape on the right 'kiki'.

The claim that sound-meaning correlations can be nonarbitrary gained a lot of attention recently in 2016, after of the work of Blasi et al.

"By analyzing word lists covering nearly two-thirds of the world's languages, we demonstrate that a considerable proportion of 100 basic vocabulary items carry strong associations with specific kinds of human speech sounds, occurring persistently across continents and linguistic lineages (linguistic families or isolates)." (Blasi et al., 2016b)

More recently Cuskley et. al. examined the literature on the "kiki-bouba effect" and observed that most accounts pointed to the mapping between acoustic or articulatory properties of sound and shape. According to them, previous studies failed in consider that, for the literate subject, the influence of the shapes of the graphemes could function as an underlying matching mechanism. It is possible that as the traditional alphabets evolved, the congruent shapes were biased against incongruent ones.

"We compare traditional accounts of direct audio or articulatory-visual mapping with an account in which the effect is heavily influenced by matching between the shapes of graphemes and the abstract shape targets. The results of our two studies suggest that the dominant mechanism underlying the effect for literate subjects is matching based on aligning letter curvature and shape roundedness (i.e. non-words with curved letters are matched to round shapes). We show that letter curvature is strong enough to significantly influence word-shape associations even in auditory tasks, where written word forms are never presented to participants." (Cuskley et al., 2015)

Even with so much evidence that supports some kind of motivated sound-shape mapping, many important questions remain. What is the basis for cross-modal matching: entire words, segments, the transition between segments or phonological features? What is the dominant iconic ground for the mappings? How is the crossmodal mapping achieved? What is the role of the Vision, Proprioception, Haptic senses and literacy in mapping sounds to meaning? Besides that, what does it mean? What are the implications for linguistics, semiotics, neurolinguistics, psychology, literacy, dyslexia and speech disorders?

To answer those questions goes way beyond the objective of this paper. Our goal is to demonstrate how uniskript alphabets incorporate many of the sound-shape correspondences strongly supported by research. The literature indicates, for instance, that front and closed vowels are associated with the concept of "smallness", while open and back vowels are associated with the concept of "largeness". The front closed vowel 
in uniskript is represented by a smaller shape, while open vowels are represented using bigger shapes. The number of lines used mirrors the association between the sounds and conceptual size. The curve in the back vowels also makes them look bigger than the front vowels. The "fullness" associated with bilabial sounds in Blasi et al (Blasi et al., 2016a) is represented in uniskript by using ellipses for $\mathrm{p}$, b, and $\mathrm{m}$.

Additionally, anterior high vowels are usually associated with the concept of "sharp", or "spiky", while back vowels are associated with the concepts of "roundness" and "smoothness". Front and back vowels are differentiated in uniskript by the use of straight angles versus curved lines, matching the concepts or "sharp" and "smooth" respectively.

For the literate subject, the printed page is perceived as a metaphor for the physical space around them. In the western world, where the directionality of writing is from left to right, the left side of the printed shape is perceived as its "front", while the right side of a printed shape is perceived as its "back". Based on this perception, uniskript represents the backward movement of the tongue in the articulation of the back vowels by placing the curve at the right side of the glyph.

\section{General Applications}

By combining featural-shape indexicality and sound-shape congruency, uniskript alphabets provide transparent and intuitive writing systems, which can be applied in a variety of different contexts.

According to Shukla (Shukla, 2016a), the possibility of "inventing novel teaching methods" which would take advantage of the Kiki-Bouba effect to reinforce the cross-modal integration of abstract concepts could significantly improve education:

Complex concepts typically take time to be thoroughly encoded and espoused by students. Shortening the time invested in learning while reducing the rate at which conceptual learning is blurred/forgotten would subsequently raise the standard of education for all types of people in all types of settings. (Shukla, 2016b)

Literacy methods could also take advantage of those cross-modal bias to make learning how to read easier (Rebecca Welles, 2015). Different versions of uniskript alphabets have been used in the last ten years as a tool to develop meta phonemic awareness and to teach the alphabetic principle to pre-literate children. ELA teachers report that kindergarten and first-grade children in the Navajo Reservation exposed to uniskript phonics from 2017-2018 tested better on the Arizona Standards Reading Foundations for ELA compared to children in the previous years who were not exposed to it (Polido, 2018).

First-grade students of Kapuna School in the Gulf Province in Papua New Guinea received uniskript classes. The teacher reports that: 
"After 5 weeks I had most of them starting to blend and write words for stories. I left them at that point, but Rosa continued giving them practice, and by September when I checked them again they could write one sentence stories in both Koriki Uniskript and English. This is a far faster acquisition of literacy than the Kapuna Year Two class described above - half a year versus, one and a half years. I think they are probably the most advanced first-year class in the province." (Robert Petterson, 2014)

When used as a phonics method to teach literacy, uniskript instructors use specific manual gestures to accompany each one of the visual shapes. Each gesture is carefully designed to mimic both, the process of articulation in the mouth and the visual shape proposed for the phoneme. The aim of the program, in this case, is to explore cross-modal correspondences involving auditory, visual and haptic senses simultaneously, so students experience learning in a sensorial and intuitive way. To discuss the evidence on mouth-hand neurological mappings is beyond the scope of this working paper, but I want to shortly mention that research has shown connections between the mouth and manual movements. Vainio et al. (Vainio et al., 2018) propose that:

"the movements of the tongue body, operating mainly for vowel production, share the directional action planning processes with the hand movements. Conversely, the tongue articulators related to tongue tip and dorsum movements, operating mainly for consonant production, share the action planning processes with the precision and power grip, respectively."

Some of the manual gestures used to teach Uniskript English are illustrated in Figs. 5, 6 and 7 below:

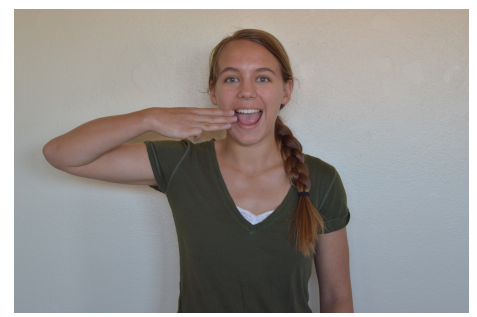

Figure 5: The maximum degree of opening of a vowel is mimicked by the use of three fingers representing the concept of largeness.

Besides the common use of uniskript as a tool for literacy, there are anecdotical data pointing to the efficacy of uniskript in remediating reading in children with autism and dyslexia. Two cases that I want to mention are from the UofN in Kona, Hawaii. It took only two weeks for B. W. D., an autistic 21-years-old man to learn how to read and write in uniskript (C. Lima, personal communication, January 20, 2013). After that, his mother reported that he would spontaneously spend up to 5 hours per day writing texts in uniskript and 


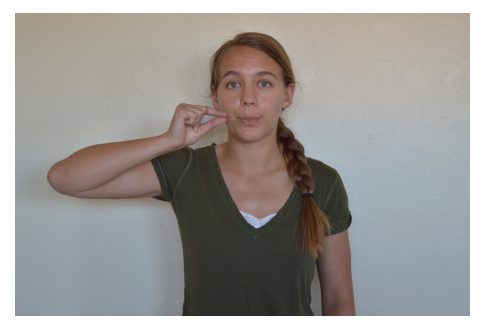

Figure 6: The closing of the lips in a bilabial consonant is mimicked by the fingers doing a small grasping movement, representing the concept of smallness.

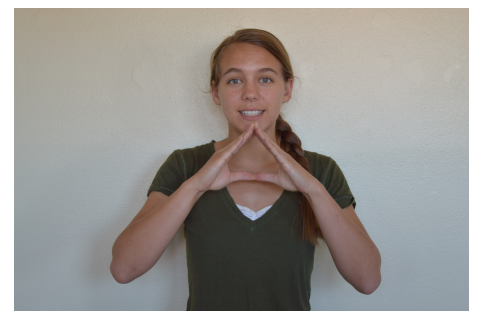

Figure 7: The raising of the tip of the tongue in the articulation of an alveolar consonant is mimicked by the manual gesture of triangle pointing up, representing the concept of harshness/pointy.

that L. W. D.'s ability to read texts using Roman letters improved significantly (Suzanne Davison, personal communication, September 13, 2013).

A group of speech therapists in San Francisco area who attended to a workshop by the Uniskript Research \& Literacy Institute in 2014 reported later that, by using uniskript in only one session, the patients would develop phonemic awareness equivalent to four sessions using traditional methods (Bob Norsworthy, personal communication, March 17, 2014).

M. R, a dyslexic 13-year-old girl from the International Christian School Kailua-Kona, learned the logic of uniskript letters in two weeks and then helped design the basis of the uniskript English alphabet. After many years struggling to read Roman letters, she could read uniskript with ease and even teach it to other kids. She reported later that reading in uniskript felt like finally putting on comfortable shoes (Bob Norsworthy, personal communication, March 17, 2014).

\section{Uniskript ESL}

Another proposed application of uniskript is as a tool to teach pronunciation to adult second language learners. In 2017, during the PSLLT Conference - Bridging L2 Pronunciation Research and Teaching, and the Research Methods in Second Language Pronunciation Workshop, at the University of Utah, there was a general perception among the researchers that there is a lack of research on effective methods to teach pronunciation at the segment level. The use of IPA is usually rejected by students, who find its symbols 
clumsy and hard to memorize. According to (Franklin and McDaniel, 2016) "the lack of empirical studies addressing pronunciation instruction" constitutes one of the greatest challenges reported by experts in the field of adult pronunciation.

My hypothesis is that the featural-visual indexicality and the sound-shape congruency properties of uniskript can make it a useful tool to teach methaphonological awareness in both L1 and L2.

\begin{abstract}
"The term metaphonological awareness is understood by the author as consisting of the explicit knowledge of selected aspects of L2 phonetics and phonology, analytic awareness of the formal properties of the target language as contrasted with the learners' L1 as well as a considerable level of processing control, i.e. intentional focus on phonetic forms and articulatory gestures during speech performance. In a longterm empirical study Wrembel [11] demonstrated that meta-awareness raising and conscious acquisition of explicit knowledge contributes to the development of L2 pronunciation competence more than pronunciation instruction devoid of metacognitive reinforcement." (Wrembel, 2010)
\end{abstract}

With the objective of illustrating the general concept of uniskript for the readers, I will introduce now the uniskript ESL alphabet. Using a one-to-one correspondence to represent the most salient phonological features of the Cot-Caught Merger dialect of American English, I will demonstrate how each one of the uniskript glyphs reflects featural-visual indexicality as well as sound-shape congruency. Uniskript ESL differs from the uniskript English alphabet used for vernacular literacy use in the way it treats the vowels.

The first distinction in the glyphs is between vowels and consonants. Vowels are generally represented by the use of lines, representing the free flowing of the air that characterizes its production. Consonants are represented by the use of a variety of plan geometric shapes, representing the organ where the occlusion occurs or the acoustic effect caused by the impediment to the air flow.

\begin{tabular}{|c|c|}
\hline \multicolumn{2}{|c|}{ Constant-vowel Distinction } \\
\hline VOWELS & CONSONANTS \\
$\equiv$ & $\ominus$ \\
$=$ & $\Delta$ \\
= & $\approx$ \\
- & $\odot$ \\
\hline
\end{tabular}

Figure 8: Vowels are produced with a free flow of air and are thus represented by lines. Consonants are produced with an impediment to the air flow by one of the speech organs - uniskript represents the organ producing the occlusion using different shapes. 


\section{Short Vowels}

Let us examine the vowels of the Cot-Caught Merger dialect of English organized in uniskript according to their phonological features and their cross-modal correlations. The phonological analysis of English vowels employed to generate the uniskript ESL considers an inventory composed of six short vowels: æ, e, I, 'a, andU. (Roach, 1984). Inhisanalysis, thesesixbasicvowelsoccupyone moraandneedtobe followedbyaconsonantinthe cod

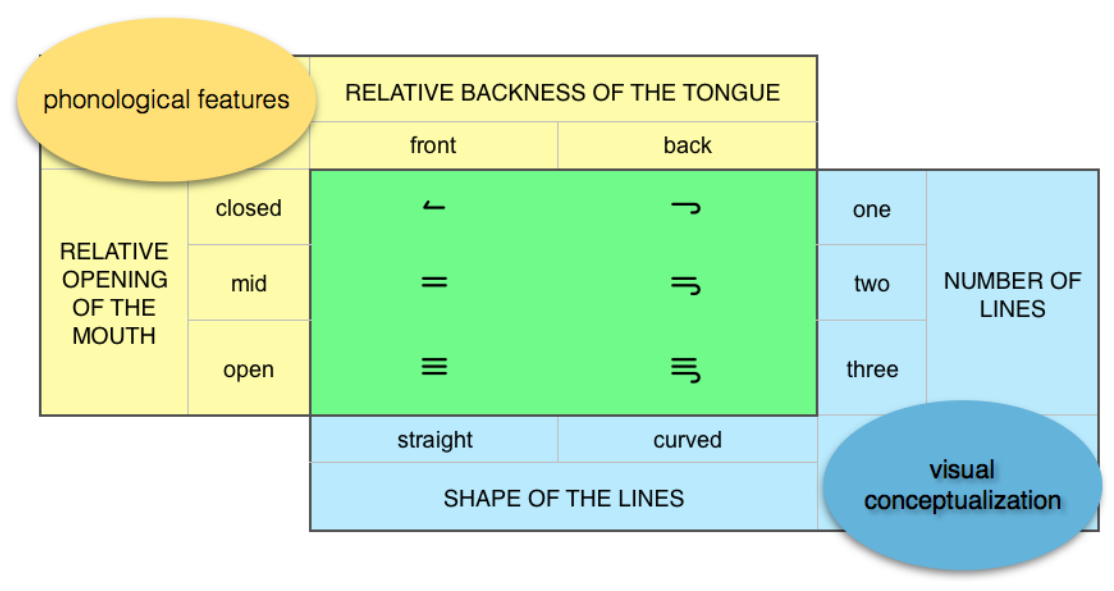

Figure 9: In the representation of the short vowels, the number of lines mirrors the relative opening of the mouth, while the shape of the lines mirrors the relative backness of the tongue.

Figure 10 shows the short vowels, which are also plain, or stable - they start and end with the same quality. For each vowel the chart shows the relevant phonological features in the first column, the uniskript glyph in the second, the phonological segment using IPA, one of the most common graphemes using in the English orthography to represent the sounds, and a keyword.

\begin{tabular}{|l|c|c|c|c|}
\hline & \multicolumn{5}{|c|}{ SHORT (PLAIN) VOWELS } \\
\hline UniSkript & IPA & $\begin{array}{c}\text { common } \\
\text { grapheme }\end{array}$ & keyword \\
\hline front closed & - & {$[\mathrm{I}]$} & $\mathrm{i}$ & pit \\
\hline front mid & $=$ & {$[\varepsilon]$} & $\mathrm{e}$ & pet \\
\hline front open & $\equiv$ & {$[\Re]$} & $\mathrm{a}$ & pat \\
\hline back closed & $\supset$ & {$[\mho]$} & $\mathrm{u}$ & put \\
\hline back mid & $\equiv$ & {$[\Lambda]$} & $\mathrm{u}$ & putt \\
\hline back open & $\equiv$ & {$[\mathrm{a}]$} & 0 & pot \\
\hline
\end{tabular}

Figure 10: Uniskript ESL representation of the 6 vowels of the Cot-Caught Merger Dialect. 
The uniskript glyphs used to represent the vowel in Figure 10 employ the following visual-featural indexicality and sound-shape congruency correspondences:

1. Lines to represent the air flowing freely.

2. A different number of lines to represent different degrees of opening of the mouth.

3. Curves at the left side of the glyphs to indicate tongue backness.

4. An angle at the right side of the front closed vowel represents sharpness.

\section{Long Vowels and Semivowels}

Long vowels are made by combining one of the short vowels above with one of the two semivowels present in the English inventory of phonemes. In order to explain the long vowels, we need to look at the semivowels first, displayed in the chart below.

\begin{tabular}{|l|c|c|c|l|}
\hline & \multicolumn{4}{|c|}{ SEMIVOWELS } \\
\hline UniSkript & IPA & $\begin{array}{c}\text { common } \\
\text { grapheme }\end{array}$ & keyword \\
\hline labiovelar & $\circ$ & {$[\mathrm{w}]$} & $\mathrm{w}$ & wasp \\
\hline palatal & $n$ & {$[\mathrm{j}]$} & $\mathrm{y}$ & yap \\
\hline
\end{tabular}

Figure 11: Uniskript ESL representation of the 2 semivowels of the Cot-Caught Merger Dialect.

Semivowels, as the name suggests, are segments that are vowel like in terms of articulation, but function as consonants. Similar to the vowels, there is no obstruction to the airflow in their articulation. But similar to the consonants, they never occupy the nucleus of a syllable.

The two semivowels in English are distinguished in uniskript by representing the main organ involved in its articulation. The lips are distinctively rounded in the pronunciation of $\mathbf{w}$, while the center of the tongue is distinctively raised to pronounce the $\mathbf{y}$. The uniskript glyphs to represent them employ the following visual-featural indexicality and sound-shape congruency correspondences.

1. A circle represents the rounding articulation of the lips in the labiovelar semivowel. At the same time, both velar and labial sounds are cross-sensory perceived as rounded.

2. A half hexagon represents the raised articulation of the tongue in the palatal semivowel. At the same time, palatal sounds are cross-sensory perceived as angular and sharp.

Now, that we have explained how the semivowels are represented, let us examine how they are combined with the short vowels to form the long vowels of the English inventory. 
Short vowels are phonetically plain, while long vowels are phonetically glided. It means that there is a slight change in the quality of the vowel throughout its articulation. Long vowels start with one quality and end with another quality. They are technically diphthongs, even though some of them are not perceived as such by native speakers of English. uniskript ESL is designed to help second language learners to articulate the vowels with a accuracy, so they need to be trained to produce the diphthongs even where they are not phonological. Uniskript approaches this problem by combining a short vowel and a semivowel to represent the gliding or changing quality of the long vowels in English. Let us start by looking at the long vowels that end with a pronounced rounding of the lips, as shown in Figure 12 below.

\begin{tabular}{|l|c|c|c|c|}
\hline \multicolumn{5}{|c|}{ ROUNDED GLIDES/DIPHTHONGS } \\
\hline & UniSkript & IPA & $\begin{array}{c}\text { common } \\
\text { grapheme }\end{array}$ & keyword \\
\hline back closed + rounding & $\supset \circ$ & {$[\mathrm{Uw}]$} & oo & boot \\
\hline back mid + rounding & $5 \circ$ & {$[\Lambda \mathrm{w}]$} & oa & goat \\
\hline front open + rounding & $\equiv 0$ & {$[\mathrm{aw}]$} & ow & cow \\
\hline
\end{tabular}

Figure 12: Uniskript ESL representation of 3 long vowels of the Cot-Caught Merger Dialect.

In the conceptualization of the three long vowels above, uniskript glyphs employ the following visual-featural indexicality and sound-shape congruency correspondences:

1. The extra length of the vowel is reflected visually through the juxtaposition of two glyphs.

2. The number of lines represents the degree of opening of the mouth at the articulation of the beginning vowel.

3. The circle on the right side represents the rounding of the lips at the end of the articulation of the long vowels.

4. The curve in the right side of the first glyph represents the backness of the vowels since back vowels are perceived cross-sensory as rounded.

The same process is used to represent the English long vowels that end with a palatalization, as can be observed in Figure 13.

\begin{tabular}{|l|c|c|c|c|}
\hline \multicolumn{4}{|c|}{ PALATAL GLIDES/DIPHTHONGS } \\
\hline & UniSkript & IPA & $\begin{array}{c}\text { common } \\
\text { grapheme }\end{array}$ & keyword \\
\hline front closed + palatalization & $-n$ & {$[\mathrm{ij}]$} & ee & bee \\
\hline front mid + palatalization & $=n$ & {$[\mathrm{ej}]$} & ay & bay \\
\hline back open + palatalization & $\equiv n$ & {$[\mathrm{j}]$} & ie & pie \\
\hline rounding + palatalization & on & {$[\mathrm{j}]$} & oy & boy \\
\hline
\end{tabular}

Figure 13: Uniskript ESL representation of 4 long vowels of the Cot-Caught Merger Dialect. 
In the conceptualization of the four long vowels above, uniskript glyphs employ the following visual-featural indexicality and sound-shape congruency correspondences:

1. The extra length of the vowels is reflected visually through the juxtaposition of two glyphs.

2. The number of lines represents the degree of opening of the mouth at the beginning of the articulation of the vowel.

3. The half hexagon in on the right side represents the raising of the center of the tongue at the end of the articulation of those long vowels.

4. The curve in the right side of the first glyph represents the backness of the vowels. An angle at the left side of the front closed vowel represents sharpness.

Consonant with the evidence found in the sound-symbolism literature, and as a general rule in the uniskript representation of long vowels, sharpness is associated with long vowels ending in an "i-like" sounds and roundness is associated with long vowels ending in a "u-like" sounds.

\section{Stops and Affricates}

Let us now examine the English consonants organized according to their phonological features and crossmodal correlations. The first chart introduces all the plosive consonants, including the affricates. For each consonant, the chart in Figure14 shows the relevant phonological features in the first column, the uniskript glyph in the second, the phonological segment using IPA, a common grapheme using in the English orthography to represent the sounds, and a keyword.

\begin{tabular}{|c|c|c|c|c|}
\hline \multicolumn{5}{|c|}{ OBSTRUENT CONSONANTS } \\
\hline & UniSkript & IPA & $\begin{array}{c}\text { common } \\
\text { grapheme }\end{array}$ & keyword \\
\hline voiceless labial plosive & $\ominus$ & {$[\mathrm{p}]$} & $\mathrm{p}$ & pee \\
\hline voiced labial plosive & $\Theta$ & {$[\mathrm{b}]$} & $b$ & bee \\
\hline voiceless alveolar plosive & $\Delta$ & {$[\mathrm{t}]$} & $t$ & toe \\
\hline voiced alveolar plosive & $\Delta$ & [d] & $d$ & dough \\
\hline voiceless palatal affricate & $\mathscr{F}$ & {$[\mathrm{t}]$} & ch & cheese \\
\hline voiced palatal affricate & $\approx$ & [d] & j & jeep \\
\hline voiceless velar plosive & ר & {$[\mathrm{k}]$} & $\mathrm{k}$ & coat \\
\hline voiced velar plosive & $\ni$ & [g] & $\mathrm{g}$ & goat \\
\hline
\end{tabular}

Figure 14: Uniskript ESL representation of the 8 obstruent consonants of the Cot-Caught Merger Dialect. 
Plosives are produced with a total impediment in the vocal tract caused by a constriction organ. Uniskript uses plan geometric shapes to represent the constriction organ involved, employing the following visualfeatural indexicality and sound-shape congruency correspondences:

1. A horizontal ellipse with a line crossing it sideways represents the closure of the lips in the bilabial consonants. At the same time, labial sounds are cross-sensory perceived as rounded or full.

2. An isosceles triangle represents the tip of the tongue pointing up in the articulation of the alveolar consonants. At the same time, coronal sounds are cross-sensory perceived as "angular" and "sharp".

3. A half ellipse represents the central part of the tongue going up to produce palatal consonants. The palatal affricates, due to their acoustic effects, are perceived as softer, or smoother sounds. This characteristic is iconic with the roundness of its shapes.

4. A right angle represents the dorsum of the tongue moving backward to produce a velar plosive. At the same time, the curved vertex is iconic with the roundness or smoothness of the back sounds.

5. A dot in the center of the consonant refers to the Adam's Apple, the point where the vibration of the vocal folds can be felt with the index finger. At the same time, the dot makes the shape look visually heavier, or crowded, in consonance with the cross-modal perception that voiced consonants are heavier than the voiceless one.

\section{Nasals}

Labial, alveolar and velar consonants can be produced with a nasal articulation, creating nasal phonemes.

The chart below shows these consonants, with two dots over them to represent the nostrils.

\begin{tabular}{|l|c|c|c|c|}
\hline \multicolumn{5}{|c|}{ NASAL CONSONANTS } \\
\hline labial & UniSkript & IPA & common grapheme & keyword \\
\hline alveolar & $\ddot{\theta}$ & {$[\mathrm{m}]$} & $\mathrm{m}$ & map \\
\hline velar & $\ddot{\Delta}$ & {$[\mathrm{n}]$} & $\mathrm{n}$ & nap \\
\hline
\end{tabular}

Figure 15: Uniskript ESL representation of the 3 nasal consonants of the Cot-Caught Merger Dialect.

\section{Fricatives}

The fricative consonants are represented with shapes which are more related to acoustic features than articulatory ones. 


\begin{tabular}{|c|c|c|c|c|}
\hline \multicolumn{5}{|c|}{ FRICATIVES } \\
\hline & UniSkript & IPA & $\begin{array}{l}\text { common } \\
\text { grapheme }\end{array}$ & keyword \\
\hline voiceless alveolar & $\sim$ & {$[\mathrm{s}]$} & $\mathrm{m}$ & soup \\
\hline voiced alveolar & $\dot{\sim}$ & {$[z]$} & $\mathrm{n}$ & zip \\
\hline voiceless palatal & $\approx$ & [S] & $\mathrm{ng}$ & sheep \\
\hline voiced palatal & $\dot{\approx}$ & {$\left[\mathrm{d}_{3}\right]$} & si & vision \\
\hline glotal & $\Theta$ & {$[\mathrm{h}]$} & $\mathrm{h}$ & hat \\
\hline voiceless labiodental & $\sqcup$ & {$[\mathrm{f}]$} & $f$ & fat \\
\hline voiced labiodental & كا & {$[\mathrm{v}]$} & v & vet \\
\hline voiceless interdental & 㟧 & {$[\theta]$} & th & thick \\
\hline voiced interdental & 㟧 & [ð] & th & this \\
\hline
\end{tabular}

Figure 16: Uniskript ESL representation of the 9 fricative consonants of the Cot-Caught Merger Dialect.

1. A single tilde is used to represent the friction of the air passing through a narrow opening in the oral cavity in the articulation of the alveolar fricative.

2. As the perceived amount of friction is higher in the articulation of a palatal fricative, a double tilde is used.

3. A single tilde is also used to represent the friction caused by a narrowing of the glottis in the articulation of the glottal fricative. In this case, the tilde is placed inside a circle which represents the throat.

4. As a general rule, fricative shapes are smaller than stops shapes, in consonance with the perception that fricatives are perceptually lighter than stops.

5. The tilde also points to the notion of movement, perceptually present in the articulation of the fricative sounds.

6. In the dental fricatives, open squares resembling teeth are used to represent the place of articulation where the friction is produced.

\section{Liquids}

Finally, uniskript represents the liquid consonants using lines depicting the movement of the tongue. In the articulation of the liquids, the tongue produces a partial occlusion in the oral cavity, resulting in a resonant vowel-like sound. The articulation of the liquids is considered displaced because the articulator changes its neutral configuration.

1. The backward movement of the tip of the tongue in the retroflex liquid is represented by a line curved rightward. The use of a curved line to represent the retroflex is in consonance with Blasi et 


\begin{tabular}{|c|c|c|c|c|}
\hline \multicolumn{5}{|c|}{ LIQUIDS } \\
\hline & UniSkript & IPA & $\begin{array}{l}\text { common } \\
\text { grapheme }\end{array}$ & keyword \\
\hline retroflex & ع & {$[\mathrm{r}]$} & $r$ & rat \\
\hline lateral & 入 & {$[\mathrm{I}]$} & I & Iap \\
\hline
\end{tabular}

Figure 17: Uniskript ESL representation of the 2 liquids of the Cot-Caught Merger Dialect.

all, (2016), who found out that words for "round" usually have an $\mathbf{r}$ sound. Plato referred to the notion of motion of the $\mathrm{r}$ sound.

2. The narrowing of the tongue, as it points up in the articulation of the lateral liquid is represented in uniskript as a two concave lines touching each other at the top.

I end this section by presenting Figure 18, which shows a list of monosyllabic words of different syllable templates, where $\mathrm{C}$ stands for a consonant, $\mathrm{V}$ for a vowel and $\mathrm{S}$ for a semivowel. The syllable templates are shown in the first column, the Uniskript transcription in the second column, the IPA transcription in the third column and the word in the Roman Alphabet in the fourth column.

\begin{tabular}{|c|c|c|c|}
\hline \multicolumn{4}{|c|}{ Word List } \\
\hline $\begin{array}{c}\text { CVS } \\
\text { Template }\end{array}$ & $\begin{array}{c}\text { UniSkript } \\
\text { transcription }\end{array}$ & IPA & $\begin{array}{c}\text { Roman } \\
\text { Alphabet }\end{array}$ \\
\hline CVC & $\Delta \equiv \ominus$ & [tæp] & tap \\
\hline CVC & $\theta=\Delta$ & [pet] & pet \\
\hline CVC & ๑-ר & [plk] & pick \\
\hline CVC & $\ddot{\theta} \equiv \ominus$ & [map] & mop \\
\hline CVC & $\ddot{\theta}=\ni$ & {$[\mathrm{m} \wedge \mathrm{g}]$} & mug \\
\hline CVC & ๑า & [buk] & book \\
\hline CVS & $\sim<n$ & [sij] & sea \\
\hline CVS & $\dot{\sim} \supset 0$ & [zuw] & zoo \\
\hline CVS & $\lambda=n$ & [lej] & lay \\
\hline CVS & ç0 & [rəw] & row \\
\hline CVS & $\ominus \equiv n$ & [baj] & buy \\
\hline CVS & \rceil$\equiv 0$ & [kaw] & cow \\
\hline
\end{tabular}

Figure 18: List of monosyllabic words in uniskript ESL.

The idea is not to replace the Roman letters in an ESL teaching program, but to use uniskript as a tool to develop metaphonological awareness in order to improve pronunciatIon. In most situation, uniskript would be used as an sensory enhanced phonetic techique to be accessed when pronunciation problems arise, and specially when L1 interfers with L2 pronunciation. It can also be used as a pronunciation database resource where students can consult for the pronunciation of specific words. 


\section{Conclusion}

Questions have been raised in the academy as to whether sound symbolism and crossmodal correspondences could be used to facilitate learning at different levels. In this working paper, I have introduced the concept of uniskript, a methodology developed by me and my team at the University of the Nations in Kona, designed to generate alphabets that are very easy to learn due to their featural-visual indexicality and sound-shape congruency properties. Uniskript alphabets have been used in a variety of contexts, including the teaching of phonics in literacy programs, remediation programs for struggling readers, second language teaching, heritage language revitalization, among others. Programs have been developed in Papua New Guinea, Brazil, Thailand, China and in the US.

I have also discussed shortly the semiotic nature of uniskript, contrasting it with writing systems that are mainly symbolic in nature, arguing that indexicality allows for the developments of alphabets that are easier to learn an require less memorization effort. I have shortly commented on the sound symbolism literature and argued that uniskript glyphs take advantage of sensorial cross-modality, creating alphabets that are highly intuitive.

Finally, I introduced uniskript ESL to provide the reader with an opportunity to familiarize herself with one version of uniskript. One of my hypothesis is that uniskript can be very effective as a tool to teach pronunciation in a second language learning program.

This material is work in progress, submitted as a preprint, so I can get feedback from my colleagues and improve it for future publication. Some of the next steps would be to produce controlled research comparing the performance of subjects learning uniskript with subjects learning a non-congruent shape-based alphabet. We also need longitudinal studies to verify the long-term gains in reading Roman letters for kids exposed to uniskript phonics, and the long-term gains in pronunciation for L2 students exposed to uniskript. I have many questions regarding the nature of the crossmodal correlations, the role of phonology in sound symbolism, how sound symbolism relates to the evolution of language, the role of indexicality and congruency in learning, neurological mappings between manual and articulatory movements, just to list a few. Could uniskript shapes be used as a theoretical language for expressing processes and rules in phonology? I propose that uniskript alphabets can serve as a platform for research to help shed light on many of the questions that still need to be answered or even asked.

\section{Acknowledgments}

I acknowledge the support and valuable contribution of the University of the Nations in Kona. Without the ingenuity of David Hamilton, Edson M. Suzuki, Youngshin Kim, Joseph Avakian, Michael Saia and others, who have collaborated in different stages of creation and development of uniskript, it would have been impossible for me to develop the 4-Questions Technique shortly described in this work. To Edson M. Suzuki, my husband, who has an indispensable role in defining and shaping all the phonetic aspects of my research, my profound gratitude, and admiration. And thank you to the Uniskript Research \& Literacy Institute, in the person of Robert Norsworthy, for their support and inspiration. 


\section{References}

Timothy M.S. Baxter. THE THEORIES OF CRATYLUS AND HERMOGENES. In The Cratylus, pages 8-29. Brill. doi: 10.1163/9789004320796_003. URL https://doi.org/10.1163\%2F9789004320796_003.

Damián E. Blasi, Søren Wichmann, Harald Hammarström, Peter F. Stadler, and Morten H. Christiansen. Sound-meaning association biases evidenced across thousands of languages. Proceedings of the National Academy of Sciences, 113(39):10818-10823, sep 2016a. doi: 10.1073/pnas.1605782113. URL https: //doi.org/10.1073\%2Fpnas.1605782113.

Damián E. Blasi, Søren Wichmann, Harald Hammarström, Peter F. Stadler, and Morten H. Christiansen. Sound-meaning association biases evidenced across thousands of languages. Proceedings of the National Academy of Sciences, 113(39):10818-10823, sep 2016b. doi: 10.1073/pnas.1605782113. URL https: //doi.org/10.1073\%2Fpnas.1605782113.

Christine Cuskley, Julia Simner, and Simon Kirby. Phonological and orthographic influences in the bouba-kiki effect. Psychological Research, 81(1):119-130, sep 2015. doi: 10.1007/s00426-015-0709-2. URL https://doi.org/10.1007\%2Fs00426-015-0709-2.

Federico Fontana. Association of Haptic Trajectories to Takete and Maluma. In Haptic and Audio Interaction Design, pages 60-68. Springer Berlin Heidelberg, 2013. doi: 10.1007/978-3-642-41068-0_7. URL https: //doi.org/10.1007\%2F978-3-642-41068-0_7.

Amber Franklin and Lana McDaniel. Exploring a Phonological Process Approach to Adult Pronunciation Training. American Journal of Speech-Language Pathology, 25(2):172, may 2016. doi: 10.1044/2015_ajslp14-0172. URL https://doi.org/10.1044\%2F2015_ajslp-14-0172.

Guilio Lepschy. F. de Saussure Course in general linguistics, translated and annotated by Roy Harris. London: Duckworth, 1983. Pp. xx + 236. Journal of Linguistics, 21(01):250, mar 1985. doi: 10.1017/ s0022226700010185. URL https://doi.org/10.1017\%2Fs0022226700010185.

P. Monaghan, R. C. Shillcock, M. H. Christiansen, and S. Kirby. How arbitrary is language? Philosophical Transactions of the Royal Society B: Biological Sciences, 369(1651):20130299-20130299, aug 2014. doi: 10.1098/rstb.2013.0299. URL https://doi.org/10.1098\%2Frstb.2013.0299.

David Plowright. Semiotics: The Theory of Signs. In Charles Sanders Peirce, pages 51-62. Springer Netherlands, nov 2015. doi: 10.1007/978-94-017-7356-0_5. URL https://doi.org/10.1007\%2F978-94-0177356-0_5.

Marcia S. Suzuki \& Luciane Polido. Uniskript Kindergarten EOY Assessment Rock Point Community School. Uniskript Alphabets, 2018.

\& Eiling Yee Rebecca Welles. Orthographical Learning: The Impact of Cross-modal interection. Department of Psychological Sciences, The Connecticut Institute for the Brain and Cognitive Sciences, University of Connecticut, 2015.

Christophe Rico. Intoduction. In Origins of the Alphabet: Proceedings of the First Polis Institute Interdisciplinary Conference, 2015.

Peter Roach. English phonetics and phonology: a practical course. Cambridge: Cambridge University Press 1983. Pp. x, 212. RELC Journal, 15(1):117-118, jun 1984. doi: 10.1177/003368828401500113. URL https://doi .org/10.1177\%2F003368828401500113.

Debbie Petterson Robert Petterson. Failures and Successes in Literacy in Gulf Province Schools. Language 63 Linguistics in Melanesia, Vol. 32 No. 2 ISSN: 0023-1959, 2014. ISSN 0023-1959.

E. Sapir. A study in phonetic symbolism. Journal of Experimental Psychology, 12(3):225-239, 1929. doi: 10.1037/h0070931. URL https://doi.org/10.1037\%2Fh0070931. 
Aditya Shukla. The Kiki-Bouba paraddigm: When senses meet and greet. The Indian Journal of Mental Health, 2016a.

Aditya Shukla. The Kiki-Bouba paraddigm: When senses meet and greet. The Indian Journal of Mental Health, 2016b.

Marcia S. Suzuki. Uniskript: A Transparent Phonological Notation 2017 www.uniskriptalphabets.com. www.uniskriptalphabets.com.

Lari Vainio, Kaisa Tiippana, Mikko Tiainen, Aleksi Rantala, and Martti Vainio. Reaching and grasping with the tongue: Shared motor planning between hand actions and articulatory gestures. Quarterly Journal of Experimental Psychology, page 174702181773873, jan 2018. doi: 10.1177/1747021817738732. URL https://doi.org/10.1177\%2F1747021817738732.

Magdalena Wrembel. Sound Symbolism in Foreign Language Phonological Acquisition. Research in Language, 8(1):1-14, jan 2010. doi: 10.2478/v10015-010-0013-6. URL https ://doi .org/10. 2478\%2Fv10015010-0013-6. 